\title{
Isis, la Gran Maga
}

\author{
HiPólito PeCci TenRero( $\left.{ }^{*}\right)$
}

\section{RESUMEN}

La diosa Isis es una de las divinidades más importantes de

Egipto, al extenderse por el Mediterráneo continúa manteniendo esta significación.

En el texto siguiente se intenta tratar de una forma sucinta como se ha producido esta expansión, la rapidez en conseguir adeptos fuera de Egipto y la influencia no solo dentro de la sociedad, sino también dentro de la política, así como su desaparición final.

PALABRAS CLAVE Enneada, Benben, Serapeum, Meokoros, nombre secreto, cristianismo

\author{
ABSTRACT \\ The goddess Isis is one of the most \\ important divinities of Egypt, on \\ having spread over the \\ Mediterranean she continues \\ supporting this significance. \\ In the next text one is tried to treat \\ as a succinct form since this \\ expansion, the rapidity has taken \\ place in followers obtained out of \\ Egypt and the influence not only \\ inside the society, but also inside the \\ politics, aswell as his final \\ disappearance. \\ KEY WORDS \\ Enneada, Benben, Serapeum, \\ Meokoros, secret name, \\ christianism.
}

(*) D.E.A. y licenciado en Historia Antigua por la Universidad Complutense de Madrid. 


\section{INTRODUCCIÓN}

Si existe una divinidad femenina que llegó a gozar de la más alta consideración y popularidad dentro de la historia egipcia desde los momentos más tempranos hasta el período grecorromano, e incluso influyó en la religión cristiana, ésta no fue otra que Isis.

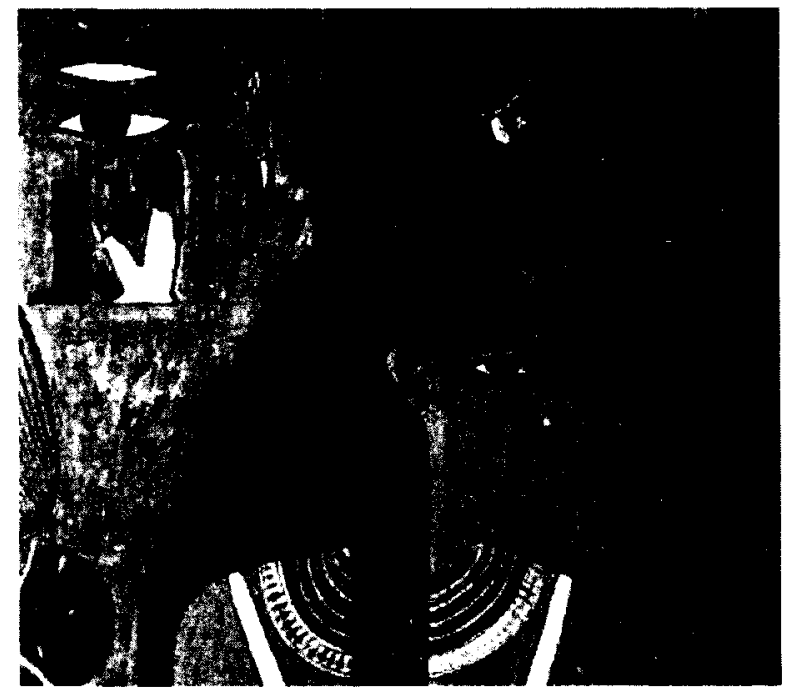

Figura 1. Isis con el trono. Tumba de Nefertari. XIX dinastia.

La diosa, que toma su nombre del trono que decora su cabeza, Aset (fig. 1), y que en época Helenística deriva a Isis, parece ser que tuvo su origen en el Delta, cobrando importancia al ser incluida en uno de los Mitos de la Creación, la Enneada Heliopolitana (fig. 2) (H. Frankfort, 1993), que se encuadra dentro de los Textos de las Pirámides datados en la V dinastía, durante el reinado de su último soberano, Unas.

Este relato, en donde se narra la génesis del mundo, cuenta como del Num u Océano Primigenio apareció el dios creador Atum, el cual engendró por masturbación al resto de los seres así como el primer trozo de materia sólida, el Benben ', excepto al dios Shu el Aire, que es escupido y Tefnut la Humedad, que fue vomitada.

Estas dos divinidades conciben a Geb, la Tierra, y Nut, el Cielo, y a su vez, de ellos surgen Osiris, Isis, Set y Neftis, dando lugar a uno de los conjuntos de dioses más importantes de la religión egipcia, a los que se suman comúnmente Horus y Anubis.

' El Benben dará origen a las formas piramidales, al igual que al piramidión, que, cubierto de pan de oro, se sitúa en lo alto de los obeliscos. 


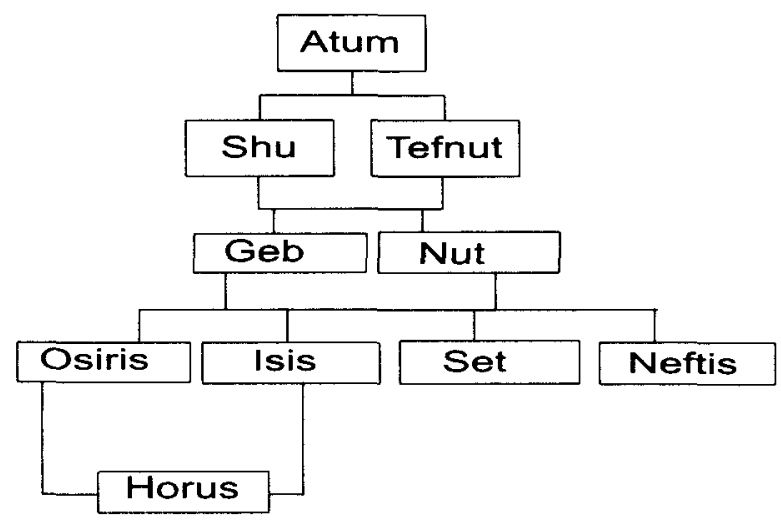

Figura 2. Enneada Heliopolitana

La importancia de esta Enneada radica en la unión de una serie de dioses que poseen rasgos de la naturaleza muy marcados, junto a otras divinidades que presentan peculiaridades humanas, todo ello presente en el hombre a través de uno de los puntales del estado egipcio, la Realeza.

Estos aspectos están muy presentes en el Mito de Osiris, que también se enmarca dentro de esta Enneada, y por el cual Isis adquiere su mayor prestigio.

En el Mito, Osiris es el rey legítimo durante la época mítica, pero su hermano Set, celoso de él, lo asesina.

Algunos autores adornan la narración, así en el siglo I d. C. Plutarco de Queronea ${ }^{2}$ cuenta que el dios, engañado por su hermano, se introduce en un baúl que es cerrado herméticamente y lanzado al Nilo, siendo arrastrado al mar ${ }^{3}$ hasta llegar a las costas de Biblos. Isis, su hermana/esposa, recupera el cofre, sin embargo en un descuido, Set descuartiza el cadáver en catorce partes y esparce los fragmentos por diferentes puntos.

La diosa emprende de nuevo su búsqueda, localizando todos los pedazos, excepto los órganos genitales, que según la tradición habrían sido devorados por un Oxirrinco, hecho por el que en algunas localidades existía la prohibición de alimentarse con la carne de este pez.

En todas las zonas en donde se encontraron restos de la divinidad su esposa levanta un sepulcro, acontecimiento que explicaría la existencia de los numerosos emplazamientos en el interior de Egipto relacionados con Osiris, como Busiris ${ }^{4}$ o Abidos, siendo ésta última la población tradicional en la cual

\footnotetext{
2 Plutarco de Queronea vivió en los siglos I y || d. C.. sus obras más importantes son "Vidas Paralelas", cuarenta y cuatro biografías de personajes romanos y griegos célebres, y "Obras Morales".

${ }^{3}$ En este aspecto hay que recordar que el Nilo fluye de Sur a Norte, desembocando en el Mediterráneo.

${ }^{4}$ Casa de Osiris.
} 
Isis encontró la cabeza del dios, por lo que se reconoció como el punto donde estaba ubicada la verdadera tumba de la deidad.

En otras narraciones se afirma que Isis, acompañada de su hermana Neftis, recorre la tierra buscando a su hermano/esposo hasta encontrar su cadáver en el rio, y lo hace resucitar ayudada por Anubis, que fue enviado, según algunas versiones, por Re para realizar su momificación.

La tradición cuenta que Isis habría tenido un hijo póstumo del dios ${ }^{5}$, llamado Horus, el cual, habría retado a su tío, perdiendo en el transcurso de la lucha un ojo, que le fue restituido por la diosa. En este aspecto, hay pasajes que hablan del Ojo derecho de Horus como representación del Sol y del Ojo izquierdo como imagen de la Luna.

Esta contienda finalizó con la mediación de los dioses, que reconocieron a Horus como sucesor legitimo de su padre Osiris, mientras que este último se convirtió, entre otras cosas, en Juez de los Muertos.

Con este mito se intenta manifestar el vínculo existente entre el soberano y los dioses, pues todo faraón ${ }^{6}$ al ser coronado se convertía entonces en el Horus Viviente, hijo de Isis, el "Gran Trono» ?, el trono deificado, para pasar a ser Osiris en el momento de su muerte.

Gracias a estas tradiciones la diosa adquiere una gran influencia, pues encarna la devoción conyugal y el amor materno, un factor que facilitará en tiempos posteriores su entrada en Roma, y asimismo sirve para que se la relacione con otra serie de divinidades femeninas.

\section{EL VÍNCULO DE ISIS CON OTRAS DIVINIDADES.}

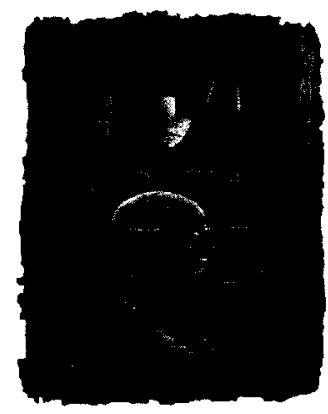

Figura 3. Isis con los atributos de la diosa Hathor.

\footnotetext{
${ }^{5}$ Aunque no explica como, pues, como antes se ha dicho, carece de órganos genitales.

${ }^{6}$ El término "faraón" no formó parte de la titulatura real. En origen significaba la "Gran Casa" (per'aa), es decir, el Palacio, pero a través de los hebreos y posteriormente de los griegos pasó a designar al monarca.

"En la Teología Menfita el término "Gran Trono" designa a Menfis (Muro o Murallas Blancas), ciudad fundada tradicionalmente por Menes, unificador (¿?) de Egipto.
} 
Isis se asocia a diversas deidades que cuentan con una serie de atributos análogos, por lo que se encuadran dentro del mismo ámbito, siendo uno de los casos más conocidos la relación existente con Hathor ${ }^{8}$, pues ésta además de estar asociada con, entre otras cosas, el amor y la música ${ }^{9}$, en ciudades como Tebas era la protectora de los cementerios y la esposa de Horus, y en su representación como diosa-vaca también es una de las personificaciones de la maternidad, amamantando a un niño, thy, relacionado también con la música y que es en realidad el nexo de unión de las dos divinidades, pues existía la idea de que era el mismísimo rey, que al alimentarse con la leche divina adquiría la prudencia, sabiduría y divinidad que necesitaba todo buen monarca.

En este contexto, Isis aparecía con los atributos de Hathor, es decir, los cuernos de vaca rodeando al disco solar (fig. 3).

De esta manera se muestra sobre todo durante la Baja Época, fundamentalmente en figuras sedentes dando de mamar a Horus.

Durante el período greco-romano existe un edificio que tiene gran relación con la maternidad de la divinidad, es el "Mammisi", o capilla en donde la diosa dio a luz y se narra la fecundación y nacimiento del rey.

Durante esta fase Isis y Hathor tienen una relación muy estrecha, puesto que al parecer la hermana/esposa de Osiris pasó a identificarse con Afrodita al aparecer portando los atributos de Hathor.

Con carácter funerario, Isis está estrechamente relacionada con su hermana Neftis, mujer de Set, pues ésta la ayudó a buscar el cuerpo de Osiris, acto recogido en las "Lamentaciones de Isis y Neftis", que los sacerdotes recitaban en las fiestas en honor del dios.

Las dos diosas suelen mostrarse una a cada lado de la momia con las alas extendidas, por lo que en muchas ocasiones se las denomina «Los Dos Milanos", puesto que en algunos relatos Isis se transformó en este ave para hacer resucitar a Osiris por medio del movimiento de sus alas.

También suelen encontrarse talladas una a cada extremo del sarcófago, o incluso pintadas en la momia.

Como diosa agraria, aparte de tener relación con su marido Osiris, que también es dios de la Vegetación y de la Resurrección, tenía vinculaciones con Renenutet (fig. 4), la cual también se enlaza a Hathor, y es una divinidad que además de estar asociada a la buena suerte, se encontraba relacionada con las cosechas, los partos y la felicidad. Se la identifica fácilmente,

${ }^{8}$ El nombre significa "Casa o Templo de Horus".

${ }^{9} \mathrm{Su}$ relación con la música hace que uno de sus atributos sea el sistro, (del lat. sistrum). Instrumento musical, de metal, piedra o arcilla; estaba constituido por un mango y por un cuadro por el que se hacian pasar unas varillas en las que se ensartaban conchas o piezas metálicas; el sonido se obtenía al agitar el instrumento. 
pues suele aparecer con cuerpo humano y cabeza de serpiente, y en algunas ocasiones aparece con un tocado de plumas.

En relación con la agricultura, Isis también se identifica como Isis-Sothis, la estrella Sirio, pues su aparición coincidía con el comienzo de la inundación del Nilo, y marcaba el comienzo del Año Nuevo, que se iniciaba el 19 de julio y contaba con tres estaciones, Akhet, o período de la Inundación, Peret, o estación de la siembra, y Shemu, o período de la cosecha, de cuatro meses de treinta días cada una, con cinco días añadidos conocidos como los "días epagómenos». No obstante desde el comienzo hubo problemas entre el año astronómico y el año civil.

La conexión de la diosa con Re se encuentra ligada al nombre. Los egipcios consideraban que éste, al igual que la sombra, formaban parte de la esencia de la persona, por lo que Isis consiguió grandes poderes gracias a que ideó una estratagema con la que consiguió descubrir el Nombre Secreto de Re, convirtiéndose en la "Gran Maga".

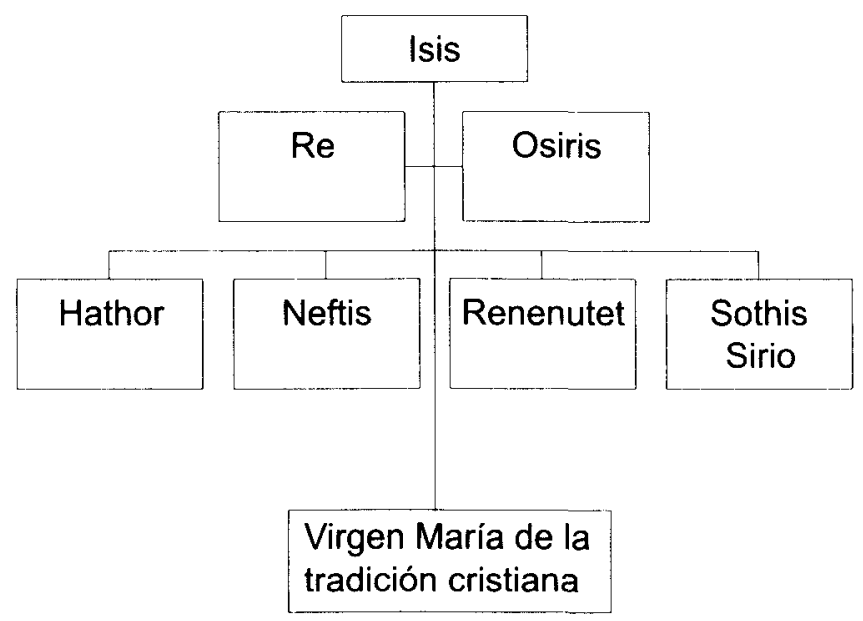

Figura 4. La relación de Isis con otras divinidades.

\section{EL PROCESO DE HELENIZACIÓN DE LA DIVINIDAD}

En el año 332 a. C., y tras haber vencido en la batalla de Issos el año anterior al rey persa Dario III Codomano, Alejandro III entra en Egipto como un libertador, comenzando el periodo de dominación griega en el país, que se extenderá hasta la muerte de Cleopatra VII el 30 a. C.

En este momento se funda la ciudad de Alejandría, ubicada en la zona occidental del Delta, en el emplazamiento de una aldea de pescadores llamada Racotis, que se convertirá en uno de los puertos más importantes del 
Mediterráneo. Isis comienza a sufrir un proceso de helenización, asimilándose a dioses y mitos griegos cuya naturaleza o bien era de tipo agrario o poseían atributos relacionados con la maternidad, como es el caso de Démeter, que además de ser la nodriza del hijo del rey de Eleusis, en donde tradicionalmente se celebran sus cultos y ceremonias, protagoniza junto a su hija Perséfone la leyenda que intenta dar respuesta a la existencia de las estaciones del año.

Este culto, al igual que el de la divinidad egipcia, se encuadra durante el período grecorromano dentro de los cultos mistéricos, reservados únicamente a los iniciados.

Igualmente, durante el período helenístico en Egipto aparece un dios que se encuentra estrechamente relacionado con Isis, es Serapis, y surge como producto de la unión de Osiris y Apis junto a una serie de elementos griegos, creado durante el reinado de Ptolomeo I Sóter ${ }^{10}$, fundador de la dinastía Lágida, que ocupa el trono en el año 305 a. C., después de las Guerras de los Diádocos, que enfrentaron a los generales de Alejandro Magno.

Se construyó un templo en honor de esta nueva deidad, conocido como el Serapeum, situándose debajo de él la necrópolis del buey Apis, manifestación de Ptah-Sokar-Osiris, y del toro sagrado Mnevis, considerado como una manifestación de Re.

En 1850 Auguste Mariette descubre el Serapeum de Menfis en Sakkarah, al norte de la pirámide escalonada de Djoser, hallando tanto elementos egipcios como griegos, sin embargo se piensa que ambos cultos se encontraban claramente separados en esta zona, no existiendo esta división en el resto de los Serapeos de Egipto, como el de Alejandría.

Durante el reinado de Ptolomeo II Filadelfo ${ }^{11}$, que se desarrolla en la primera mitad del siglo III a. C., existió en Cánope un santuario asociado a Serapis, pero también a Anubis e Isis, y ya fuera de Egipto igualmente se han descubierto diversos Serapeos, como el de Pozzuoli, en la Campania, datado en el año 105 a. C.

A finales del siglo III a. C., con Potolomeo IV Filopator ${ }^{12}$ en el trono, en las monedas ya se exhiben las figuras de Serapis e Isis, y las reinas comienzan a ser representadas con los atributos de la diosa helenizada (fig. 5), por lo que se especula con la posibilidad de que éstas fueran las encargadas de llevar a cabo los ritos del culto y los Misterios de la divinidad.

\footnotetext{
10 "Sóter" significa "Salvador" Tracia.

"Filadelfo", "El que ama a su hermana” casó con su hermana Arsinoé, viuda de Lisimaco, rey de 12 «Filópator», «El que ama al Padre».
} 


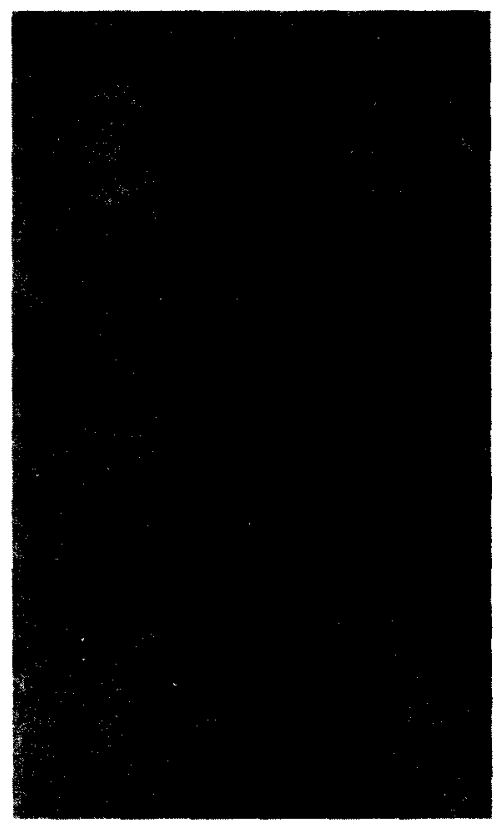

Figura 5. Representación de isis grecorromana.

\section{LA EXPANSIÓN DE ISIS POR EL MEDITERRÁNEO}

El culto a la diosa comienza a extenderse por otros territorios a través de los puertos, fundamentalmente por medio de comerciantes, soldados y esclavos, y desde aquí se propaga al interior utilizando las vías fluviales y las calzadas, pero también se especula con la posibilidad de que existieran «misioneros ambulantes» que se encargarian de difundir las nuevas creencias. Con todo, la religión es aceptada con facilidad por todo el mundo griego.

En la zona del Líbano el culto a Isis, en su forma de Isis-Hathor está muy extendido ya desde la época faraónica, aunque durante el período romano pasa a venerarse como Isis-Pharia, protectora de los marineros.

En el territorio sirio ya se conocía la devoción hacia Isis, apareciendo una inscripción fechada hacia el 145 a. C. que hace referencia tanto a la diosa como a Serapis, asimilado a Zeus-Helios.

A partir del siglo II a. C., el culto a Isis comienza a extenderse por Asia Menor, aquí, en las ciudades griegas establecidas en la Jonia aparecen gran número de inscripciones en honor a la diosa.

En la Península griega penetra por el puerto del Pireo de Atenas, en donde los emigrantes egipcios llevan el culto a Isis y a Serapis, y ya, en el año 250 a. C. aproximadamente aparece una "Asociación" de adoradores del 
dios, mientras que en Delos se levanta un Iseum durante el siglo III a. C., y en Creta en el siglo siguiente.

En Macedonia durante el siglo III a. C. se erige un templo en honor a Serapis, Isis, Harpócrates ${ }^{13}$, Anubis, y desde el siglo I a. C. también se adora a Osiris. Este templo permanece activo durante seis siglos.

Un lugar de filtración hacia el interior de la Península Itálica es la Magna Grecia, desde donde se propaga a Herculano y Pompeya, ciudad en la que existía un Iseum cercano al foro, que se encuentra adosado al teatro.

La propagación del culto también se encuentra muy estrechamente ligada al movimiento de las legiones romanas. En la expansión romana hacia el Este, el cónsul romano T. Quincio Flaminino vence en el año 197 a. C. al rey macedonio Filipo $V$ en Cinoscéfalo, Tesalia, el cual pierde todas sus posesiones de Europa y Asia, además de ser obligado a pagar una fuerte compensación de guerra y firmar una alianza con Roma. Pero esta actuación también conlleva una fuerte helenización de la ciudad italiana, lo que también favorece la expansión de Isis junto a otros cultos orientales, como Mitra.

En la Península lbérica hay evidencias de la diosa debidas a los contactos comerciales, como el vaso de la Aliseda, con fechas del 600 a. C. aproximadamente, pero fundamentalmente se puede comprobar el culto a Isis a partir de la presencia romana durante la II Guerra Púnica (218-202 a. C.) en su forma de Isis-Fortuna, junto a otras divinidades egipcias como Anubis, sin embargo el culto a Serapis es más tardio, introduciéndose hacia el siglo I a. C.

Entre los pueblos prerromanos peninsulares la divinidad no gozó de muchas simpatías, ya en época romana sus seguidores eran itálicos romanos $u$ orientales asentados en Hispania, pero en ningún caso grupos indígenas.

En el territorio de la Galia las huellas de la diosa se encuentran por primera vez en el Valle del Ródano, principal vía de paso de las legiones romanas, pero es muy posible que su culto fuese más antiguo, puesto que ya existen testimonios de su ritos en las zonas portuarias, como Marsella.

Un centro de adoración muy importante de la diosa fue Nimes, pues tras su victoria en Actium (31 a. C.) sobre Marco Antonio y Cleopatra, Augusto mandó deportar gran número de egipcios hacia esta zona, creando una gran colonia en esta ciudad, apareciendo un templo a Isis y un Serapeum. Se pueden reconocer indicios de esta colonia egipcia en el escudo actual de la ciudad, que presenta a un cocodrilo encadenado a una palmera, como símbolo de la sumisión a que fue sometido Egipto (F. le Corsú, 1997).

Aunque en París no se han encontrado ruinas de algún templo en honor a Isis, sí han aparecido algunas estatuas, como la diosa amamantando a Horus,

\footnotetext{
${ }^{13}$ Forma griega de Horus niño. En este caso es normal encontrarle con forma humana, y habitualmente con el dedo en la boca.
} 
o representaciones de Osiris y Anubis, e incluso se ha hallado una imagen del dios Bes. Asimismo se conocen citas que hablan de la existencia de un Iseum en el solar donde se levanta la iglesia de Saint-Germain, e incluso en el lugar donde está asentada la catedral de Notre-Dame que estaría consagrado a Isis-Ceres.

Entre los años 58 y 48 a. C. se producen una serie de persecuciones al culto de esta divinidad, y el Senado llega a ordenar demoler templos, estatuas y altares.

Estas persecuciones son debidas a varios aspectos, pues por una parte se ve a la diosa como una pervertidora y corruptora de la piedad, además, el misterio que la rodeaba levanta muchas sospechas por lo que se veía a su culto como un posible foco de agitaciones, debido a que en estas sociedades de iniciados existía un gran número de miembros pertenecientes a la clase baja.

Después de la muerte de César (44 a. C.), se produce el conocido como Segundo Triunvirato, formado por Octavio, Marco Antonio y Lépido. Los triunviros buscando atraerse al pueblo llevan a cabo una serie de acciones favoreciendo a la diosa egipcia, muestran símbolos isíacos en monedas, levantan un templo para su culto con fondos del Estado, etc..., todo ello implicaba el reconocimiento oficial de su religión, hecho que finalmente no se produjo.

Posteriormente comienzan las discrepancias entre Augusto y Marco Antonio, y con ello Isis pasa a ser considerada como una diosa hostil y enemiga de Roma, pues se la identifica con Cleopatra mientras que al general romano se le reconoce y se le presenta como al nuevo Dionisos.

Después de la victoria de Actium (31 a. C.) la política de Octavio se encamina a rechazar los influjos orientales, buscando con ello promover tanto la historia como las leyendas de Roma, por lo que se opone a los cultos mistéricos. En el año 28 a. C. prohíbe levantar altares a estas divinidades en el interior del pomerium ${ }^{14}$ y en el 21 a. C., en ausencia de Augusto ${ }^{15}$, con el fin de reprimir levantamientos populares, Agripa ${ }^{16}$ extiende la prohibición e impide la práctica de los ritos isiacos en un radio de $1500 \mathrm{~m}$. alrededor de Roma, al mismo tiempo junto a los judíos se produce la expulsión de los devotos y sacerdotes de la diosa.

Pero estas medidas no producen los frutos esperados, puesto que desde el principio de la época imperial el culto isiaco recibe nuevos impulsos extendiéndose por diversos territorios, además, Isis goza de gran reputación entre las clases altas en tan gran medida, que después del gobierno de Augusto muchas damas se inician en sus ritos.

\footnotetext{
${ }^{14}$ Espacio libre que se encontraba a ambos lados de las murallas de Roma en el cual estaba prohibido edificar o cultivar.

${ }^{15}$ Octavio habia recibido este título del Senado en el año 27 a. C.

${ }^{16}$ Vencedor de Actium, senador, consejero del emperador y marido de su hija Julia.
} 
En el año $19 \mathrm{~d}$. C. Tiberio desencadena la mayor persecución contra los cultos isíacos; aprovechando un escándalo ordena demoler el templo de la diosa y lanzar la estatua al Tíber sin embargo estas persecuciones no obtienen ningún fruto, puesto que aunque en Roma se pudo hacer desaparecer el culto, en el resto del Imperio es una tarea muy difícil y se continuaría practicando.

Con la subida al poder de Calígula ( $37 \mathrm{~d}$. C.) se produce un cambio en la situación, e incluso se piensa que el nuevo emperador se pudo iniciar en este culto mistérico. El César concede sus favores a la diosa levantando en el Palatino el Aula Isíaca y al año siguiente el gran Templo de Isis en el Campo de Marte, que Domiciano en el año 81 convierte en uno de los edificios más espléndidos de Roma.

Hacia el año 62 el templo de Isis en Pompeya, donde contaba con muchos adeptos al igual que en Herculano, es destruido por un terremoto, por lo que se comienza a reconstruir junto al resto de la ciudad, pero desaparece con ella en la gran erupción del Vesubio del año 79.

Con los Flavios (69 - 96), y durante el siglo II d. C. con los Antoninos (98 -192), Roma ya acepta abiertamente el culto isiaco, siendo el dominante hasta la llegada de Mitra. La diosa goza del favor de los emperadores, tanto es así, que el emperador Cómodo llegó a rasurarse como un Pastóforo y en sus monedas aparecia al lado de Isis y Serapis, pero sigue sin convertirse en un culto oficial.

A principios del siglo III, la religión Isíaca se convierte en una de las principales del Imperio, e incluso Caracalla (211 - 217) construye un gran templo para ella en el Quirinal hacia el año 215 . No obstante, en el siglo IV la popularidad de la deidad comienza a descender, por una parte, debido a la expansión de otros cultos orientales, fundamentalmente el culto al dios de origen iranio Mitra, y por otra, a causa de la subida al trono de emperadores cristianos.

Tras el Edicto de Milán (313), por el cual se concede libertad religiosa a todo el Imperio pero con un mayor apoyo al cristianismo, su culto va retrocediendo cada vez más, hasta quedar la diosa relegada a un segundo plano. La última procesión isíaca en Roma se data en el 394, en este mismo año Teodosio destruye el Serapeum de Alejandría, y en el 395 se cierra el último templo de Isis en Egipto (fig. 6), que se encontraba en la isla de Filae, con ello también desaparece el conocimiento de la lectura de los jeroglíficos, hasta que en el siglo XIX vuelve a recuperarse paulatinamente, primero en 1816 con el inglés Thomas Young y posteriormente con Jean François Champollion en 1822.

Con el emperador bizantino Justiniano $(527$ - 565) desaparece totalmente el culto a la diosa. 


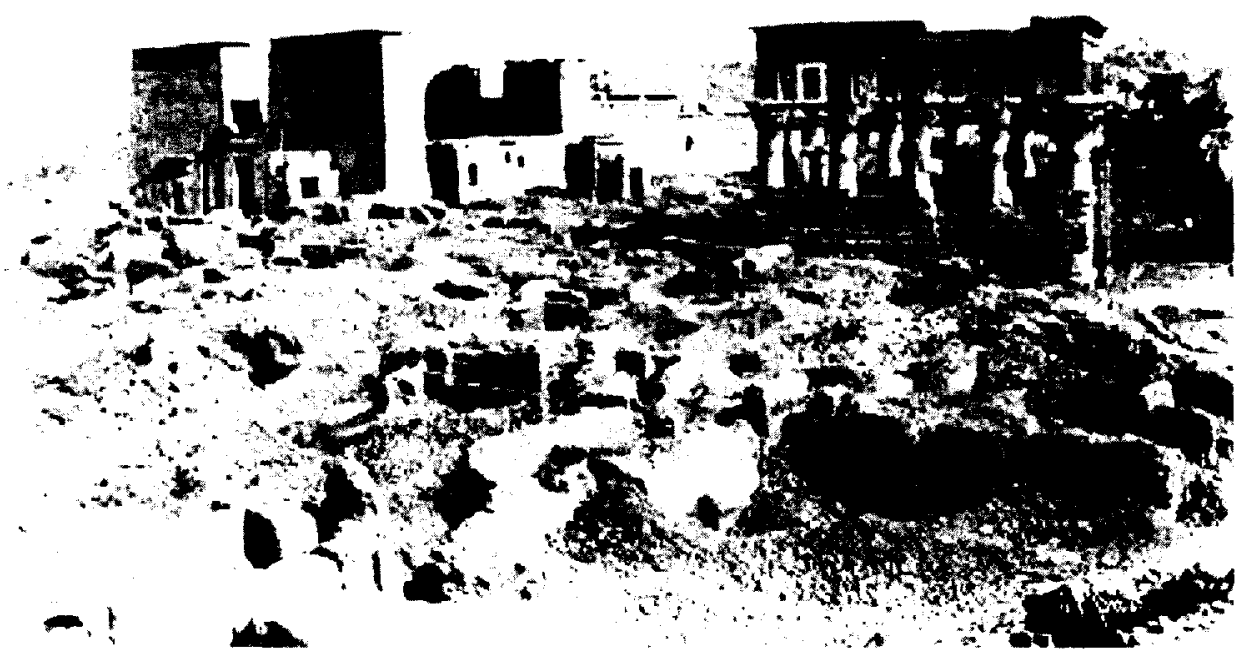

Figura 6. Templo de Isis

\section{SACERDOCIO E INICIACIÓN A LOS CULTOS ISÍACOS.}

La adoración a la diosa Isis greco-romana se encuadra dentro de lo que se denomina religiones mistéricas, por lo que sus templos están formados por espacios protegidos en donde se llevan a cabo ritos secretos conocidos solamente por los iniciados al culto.

Cuando la divinidad se establece en la Península Itálica sus mayores partidarios se encuentran fundamentalmente en las ciudades y están formados por las clases bajas, esclavos, libertos y mujeres, entre ellas un gran número de prostitutas y jóvenes en busca de relaciones sexuales, por lo que algunos personajes, como Juvenal ${ }^{17}$, no dudan en tildarla de "alcahueta».

Progresivamente, el culto va adoptando costumbres más moderadas y abandona sus rasgos libertinos, por lo que se comienza a renunciar a los placeres carnales como forma de llegar a la divinidad.

Dentro de los cultos isiacos existía un clero totalmente organizado y jerarquizado a imagen del que existía en Egipto.

Los sacerdotes se denominaban Meokoros o Herioi, y estaban formados por un alto clero, compuesto por los Profetas, en donde se incluia al Sumo Sacerdote, el cual tenía algunas prohibiciones como el celibato, y un grupo de sacerdotes, integrados por los estolistas, encargados de vestir la estatua de la diosa, hierográmatas, astrólogos, encargados de transportar el cadu-

\footnotetext{
17 Décimo Junio Juvenal, poeta satírico que vivió entre mediados del siglo I y el siglo II d. C.. Su única obra, "Satirae», está compuesta por dieciséis satiras en hexámetros, divididas en cinco libros.
} 
ceo o bastón insignia de Hermes, que en este caso se relacionaba con Thot. Por otro lado existía un bajo clero formado por cantantes, neócoros. O jardineros, interpretadores de sueños, pastóphoros, cuya misión era vigilar las capillas sagradas donde se encontraba la estatua divina durante las procesiones, y lychnóphoros, encargados durante las procesiones de portar lámparas con formas de pequeñas naves.

Existían otros cargos, como el espondóforo, responsable del vaso de oro utilizado para las libaciones, o los sacerdotes egipcios, que leían e interpretaban los ritos sagrados y eran los encargados de conseguir el agua del Nilo que se utilizaba para los rituales.

Algunos cargos sacerdotales podian llegar a ser ocupados por laicos, e incluso una persona podía ejercer diversas funciones, por lo que era normal que ciertos sacerdotes desempeñasen tareas en diferentes cultos. Del mismo modo, también existían personas sin recursos que entraban al servicio del templo.

Los servicios a la diosa eran diarios, aseándola alimentándola y llevando a cabo los sacrificios, que se realizaban dos veces al día.

Al amanecer se producía la Apertura del templo, por la que se enseñaba a los iniciados la estatua de la diosa, posteriormente el sacerdote encendía el fuego sagrado, se realizaba libaciones con el agua sagrada del Nilo y se entonaban los himnos con los que se pretendía convocar a Isis. Al mediodía se cerraba y sellaba el templo.

La iniciación no es muy conocida, ha llegado a la actualidad únicamente narrada por algunos autores latinos. Apuleyo ${ }^{18}$, autor del siglo II d. C. y gran admirador de las religiones mistéricas, afirma que las enseñanzas requerían de un largo periodo de tiempo, motivo por el que exclusivamente podía ser factible para los grupos privilegiados.

Plutarco habla de un tipo de catecumenado en el que la divinidad decidía cual era el momento propicio para comenzar el aprendizaje, para lo cual utilizaba los sueños como modo de designar a los aspirantes, que estaban obligados a cumplir unas normas previas a la iniciación, como por ejemplo respetar diez dias de castidad.

La ceremonia se realizaba de noche, en el más absoluto silencio, pues durante los ritos se producía una muerte voluntaria para abandonar la vida que se había conocido hasta ese momento y renacer en otra dedicada a la diosa.

Tras los actos, en los que se representaba el mito de Osiris, se celebraba una procesión delante de la estatua de Isis y un cambio de vestimentas, lle-

\footnotetext{
${ }^{18}$ Apuleyo vivió en el siglo II d. C., iniciado en la mayoria de los cultos mistéricos, su obra más importante es la "Metamorfosis" o "El asno de oro".
} 
gando a utilizarse hasta doce ropajes diferentes. Posteriormente se realizaba un banquete sagrado en donde se consumian alimentos que en otros momentos estaban prohibidos, como la carne de cerdo.

Las principales conmemoraciones de la divinidad se celebraban en primavera y otoño, aunque esta última es poco conocida.

Las festividades de la primavera tenían lugar el día cinco de marzo, cuando daba comienzo la época de navegación, efectuándose los actos de la Navigium Isidis, con un carnaval y posteriormente una procesión cuyo destino era el mar. En ella marchaban en cabeza mujeres que portaban vestidos blancos, seguidas por los iniciados y los sacerdotes. También se transportaban varias imágenes de la diosa y símbolos religiosos, como agua del Nilo, que simbolizaba a Osiris. Al llegar a la orilla, se consagraba una barca a Isis, en donde se colocaban diversos tipos de ofrenda y se purificaba con fuego, huevo y azufre.

Al regresar al templo se hacían votos a favor del emperador, el Senado y los caballeros, así como del pueblo romano, acto seguido, en lengua griega se proclamaba la apertura de la navegación.

Cuando comienza a extenderse el cristianismo, los primeros seguidores de esta nueva religión son paganos conversos, por lo que en su culto se introducen numerosos mitos y ritos, fundamentalmente de las religiones mistéricas, como es el caso de la influencia del mito de Osiris en la muerte y resurrección de Jesucristo, que, de la misma manera tiene conexión con los dioses agrarios y la renovación de la vegetación, o la conmemoración de su nacimiento el 25 de diciembre, lo que está igualmente relacionado con Mitra y con las fechas cercanas al solsticio de invierno.

Asimismo en la religión cristiana intervienen otros aspectos de los cultos paganos, como puede ser la conexión existente, y la asimilación de los atributos de Isis por parte de la virgen María, un rasgo claro de ello es que en numerosas ocasiones se representa en la postura sedente con el niño, a imagen de la diosa egipcia con su hijo Horus (fig. 7), el cual, en este caso podría ser identificado con la persona de Jesús.

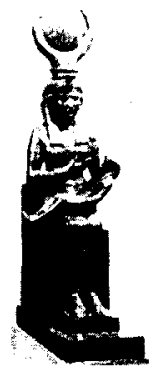

Figura 7. Isis sedente 
Utilizando como plataforma las religiones ya sólidamente asentadas, y realizando una gran labor de sincretismo, el nuevo culto tuvo el terreno abonado para conseguir una rápida expansión por todas las zonas del Imperio, y con ello la continuidad en la persona de la Virgen María de, en palabras de Apuleyo, "la Madre universal de la Naturaleza, la más grande de las diosas, Reina de los nombres, Soberana de los dioses, la que es adorada bajo múltiples nombres y múltiples aspectos», la Gran Maga, Isis.

\section{BIBLIOGRAFÍA}

Apuleyo ; El asno de Oro. Alianza Editorial. Madrid 1988.

Baltrusaitis, J. ; En busca de Isis: introducción a la egiptomanía. Serie Mayor; 6. Madrid.

Baltrusaitis, J. ; La quête d'Isis : essai sur la légende d'un mythe. Publié avec le concours du Centre National des Lettres. Paris, 1985.

Bonhéme, M. A. ; Forgeau, A.; Pharaon, les secrets du pouvoir. Paris, 1988.

Brady, T. A. ; Serapis \& Isis: collected essays. ARES. ChICAGo, 1978

Daumas, F. ; Los dioses de Egipto. Ed. Lidiun. Buenos AIRES, 1982.

HaRT, G. ; Mitos Egipcios. Ed. Akal. Madrid, 1994.

HEYOB, S. K.; The cult of Isis among women in the graeco-roman world. Etudes preliminaires aux religions orientales dans I'Empire romain. LEIDEN: BRILL, 1975.

lara Peinado, F.; El Egipto Faraónico. Ed. Istmo. Madrid, 1991.

LE CORSU, F.; ISIS, mythe et mysteres. Le Belles Lettres. PARIS, 1977.

Molinero Polo, M. A. ; Sevilla Cueva, C. ; Las instalaciones cultuales del toro Apis en Menfis: revisión de una investigación arqueológica. Espacio, Tiempo y Forma, Serie II. Historia Antigua, t. 6. MADRID, 1993.

Montet, P. ; La vida cotidiana en Egipto en tiempos de los Ramsés. ED. Temas DE HoY. MADRID, 1993.

Rubio, R. ; Isis, nuevas perspectivas. Homenaje al profesor Álvarez de Miranda. Arys: Antigüedad, Religión y Sociedades; 4. Ed. Clásicas. Madrid, 1996.

Sainte Fare Garnot, J. ; La vida religiosa en el antiguo Egipto. Buenos AIRES, 1977

TAKACS SAROLtA, A. ; Isis and Serapis in the roman World. LeIden: E. I. BriLl. 1995. 